\title{
Resolución del caso
}

\section{Ricardo Trueba}

Departamento de Resonancia y Tomografía Computada, Grupo Médico Rostagno,

Diagnóstico por Imágenes, Ciudad Autónoma de Buenos Aires, Argentina

Presentación del caso en la página 289.

\section{DIAGNÓSTICO: Miositis osificante}

\section{DISCUSIÓN}

La miositis osificante es la forma más común de osificación heterotópica, generalmente dentro de músculos grandes. Su importancia se debe, en gran parte, a su capacidad para imitar procesos patológicos más agresivos. En más del $75 \%$ de los casos, esta enfermedad se asocia a un traumatismo o antecedente de microtraumas repetitivos. En menor medida, se relaciona con procedimientos quirúrgicos y, también, se detecta en paciente con largas internaciones en terapia intensiva por traumatismo de cráneo, traumas espinales o trastornos neurológicos, incluso enfermos con quemaduras graves. Los sitios de presentación más comunes son: codo, hombro, pelvis y muslos, también puede comprometer músculos, tendones, ligamentos y aponeurosis.

Algunas afecciones están relacionadas con la miositis osificante o comparten un nombre similar, entre ellas:

- Miositis osificante circunscrita: se refiere a hueso nuevo que suele aparecer después de un traumatismo (Figuras 4 y 5).

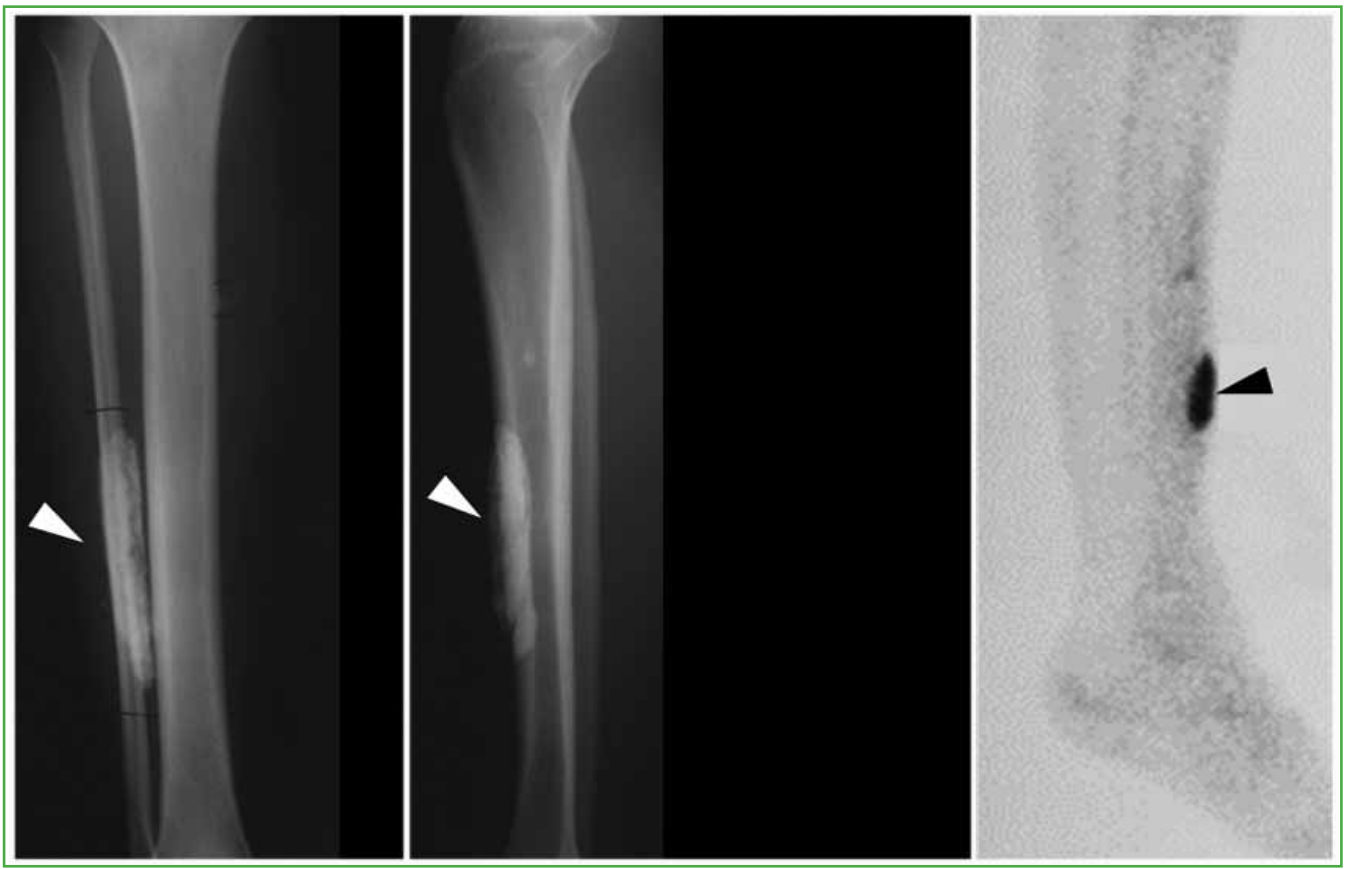

Figura 4. Miositis osificante en la fase madura. Las radiografías de pierna muestran la calcificación tibial adyacente a la diáfisis y la captación en la gammagrafía. 


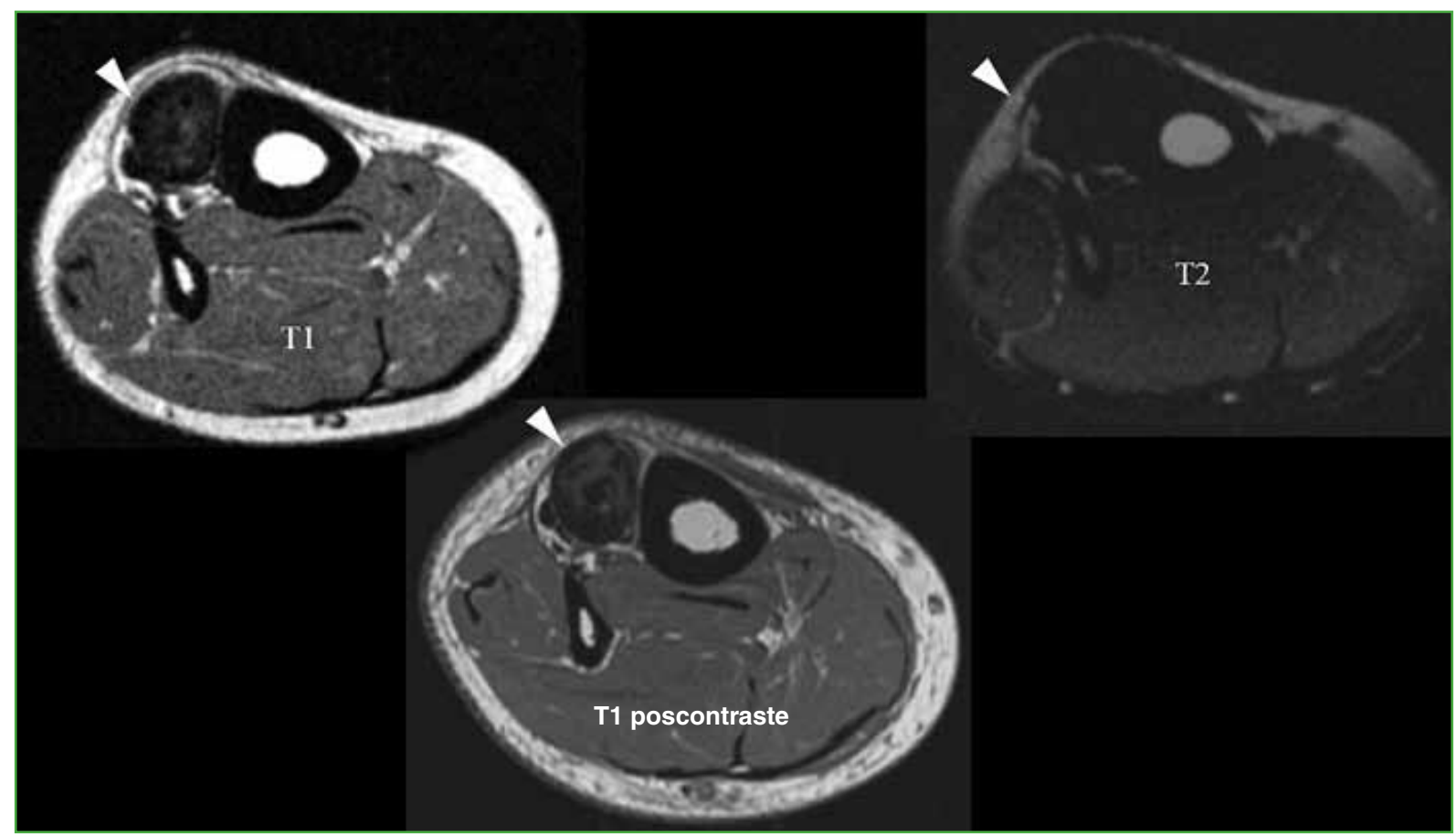

Figura 5. Resonancia magnética de pierna con medio de contraste. En las secuencias T1 y T2, se observa una imagen de baja señal adyacente a la diáfisis tibial con escaso refuerzo poscontraste.

- Miositis osificante progresiva: es un trastorno hereditario poco común que se caracteriza por fibrosis y osificación de músculos, tendones y ligamentos de múltiples sitios; es incapacitantes y, en última instancia, fatal (Figura 6).

- Paniculitis osificante: similar a la miositis osificante, pero afecta los tejidos subcutáneos.

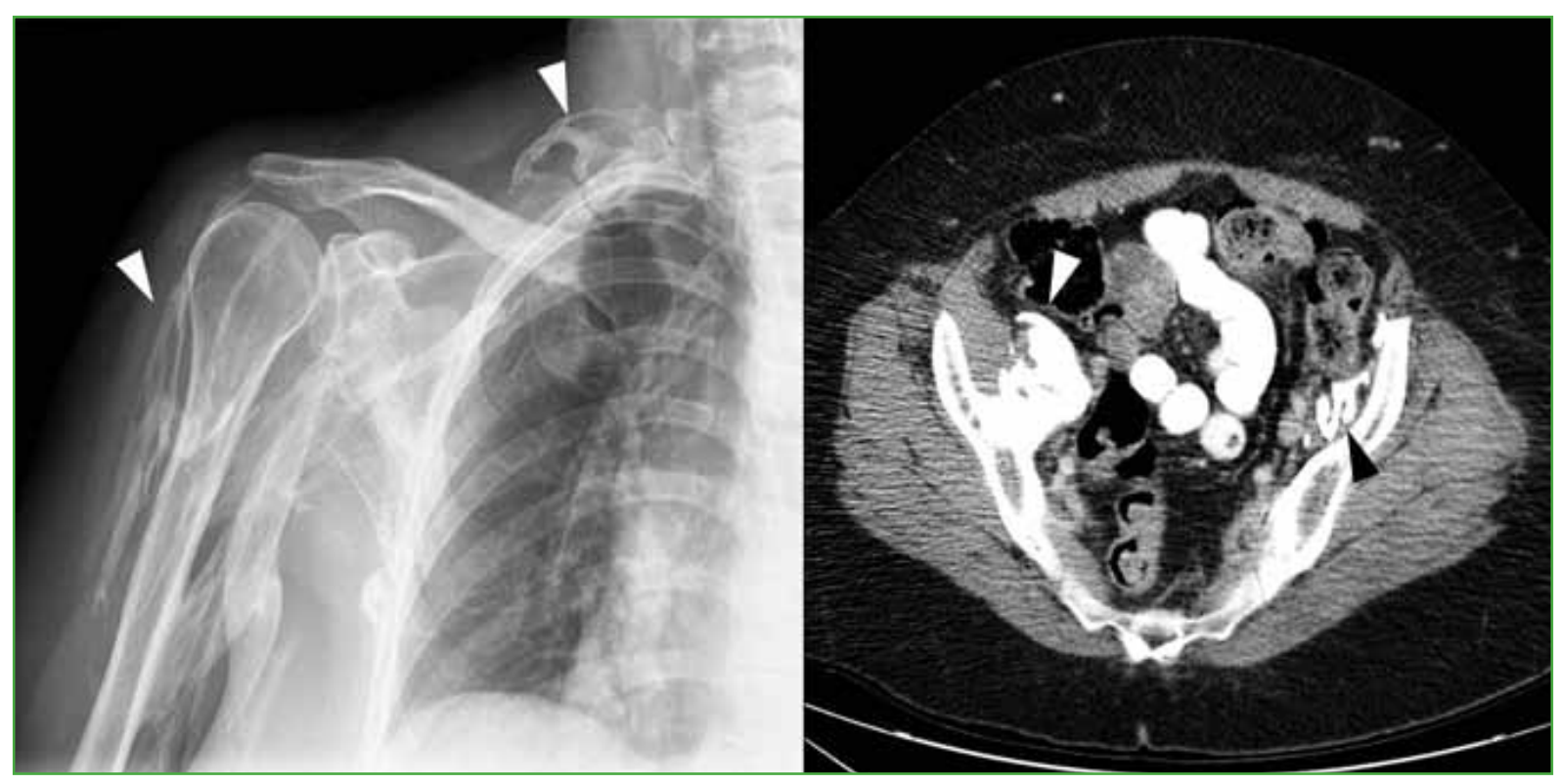

Figura 6. Miositis osificante progresiva. En la radiografía de hombro derecho, se reconocen múltiples calcificaciones de partes blandas y, en la tomografía computarizada, se aprecian calcificaciones progresivas en el psoas. 
La mayoría de los casos de miositis osificante se producen como consecuencia de un traumatismo y, por lo tanto, el grupo demográfico principal son los adultos jóvenes. Otro grupo especialmente propenso a la miositis osificante son los enfermos parapléjicos, generalmente sin evidencia de traumatismo.

Suele presentarse como una masa dolorosa, sensible y agrandada que, en el $80 \%$ de los casos, se localiza en los músculos grandes de las extremidades, a menudo, después de un trauma local reconocido, aunque no siempre se recuerda un episodio traumático definido. En los pacientes parapléjicos, no suele haber episodios traumáticos reconocidos y la enfermedad se presenta especialmente alrededor de las rodillas y las caderas. La miositis osificante es esencialmente una metaplasia del tejido conectivo intramuscular que da como resultado la formación de hueso extraóseo (sin inflamación).

Hay tres estadios histopatológicos bien descritos:

1.Primer mes: la lesión tisular provoca la organización del tejido de granulación con diferenciación fibroblástica, osteoblástica y formación osteoide.

2. Segundo mes: la matriz osteoide mineralizada se desarrolla con hueso laminar inmaduro.

3. Tercer mes: el hueso inmaduro progresa a hueso cortical y trabecular laminar maduro.

Desafortunadamente, el aspecto histológico de la miositis osificante puede parecer similar al del osteosarcoma $\mathrm{y}$, por lo tanto, puede conducir a un manejo inadecuado.

El aspecto radiográfico típico de la miositis osificante es una calcificación circunferencial con un centro brillante y una hendidura radiolúcida que separa la lesión de la corteza del hueso adyacente. En la radiografía convencional, inicialmente, no hay calcificación, pero puede haber inflamación de los tejidos blandos. La calcificación suele manifestarse en un plazo de 2 a 6 semanas y la lesión alcanza el aspecto clásico de calcificación periférica bien circunscrita a los dos meses. Durante los siguientes cuatro meses aproximadamente, por lo general, las calcificaciones se vuelven más pequeñas y densas. La hendidura radiolúcida puede ser difícil de observar en las radiografías convencionales.

La apariencia en las imágenes de la tomografía computarizada es similar a la de la radiografía convencional, lo que demuestra que la mineralización procede de los márgenes exteriores hacia el centro. La hendidura entre las calcificaciones y el hueso subyacente suele ser visible. El borde periférico de mineralización se observa en 4-6 semanas.

El aspecto en las imágenes de la resonancia magnética cambia con la antigüedad de la lesión. Las características iniciales pueden ser engañosas, porque la calcificación periférica no se visualiza bien y el edema en los tejidos blandos puede extenderse más allá del borde calcificado, a menudo, inaparente.

- T1: isointenso mal definido a la masa muscular.

- T2: periferia: señal alta (edema) observada hasta las ocho semanas; central: señal alta heterogénea, debido a la alta celularidad proliferativa y los componentes cartilaginosos. Se han informado niveles líquido-líquido y se han atribuido a hemorragias previas.

- T1 con medio de contraste: el refuerzo suele estar presente.

Las características tardías imitan al hueso:

- $\mathrm{T} 1$

- periferia: señal baja (hueso laminar maduro)

- central: señal de intermedia a alta (médula ósea)

- $\mathrm{T} 2$

- periferia: señal baja (hueso laminar maduro)

- central: señal de intermedia a alta (médula ósea)

- T1 con medio de contraste: en general, sin refuerzo en lesiones maduras.

En las primeras etapas del desarrollo de la lesión, se observa la captación aumentada inespecífica de la gammagrafía ósea que disminuye gradualmente a medida que la lesión madura.

La tomografía computarizada con emisión de positrones con FDG puede mostrar una captación intensa que imita lesiones de alto grado.

La miositis osificante es un cuadro benigno y no existen pruebas convincentes de que, alguna vez, se produzca una degeneración maligna. Como tal, el tratamiento se reserva para las lesiones sintomáticas y la resección quirúrgica suele ser curativa. 


\section{DIAGNÓSTICO DIFERENCIAL}

En los estudios por imágenes, el diagnóstico diferencial debe incluir:

- sarcomas de tejidos blandos, incluidos histiocitoma maligno o sarcoma sinovial. No hay un antecedente traumático (Figura 7).

- osteosarcoma paraostal: se calcifica en el centro y continúa hacia la periferia, y afecta más a la región metafisaria (Figura 8).

El tratamiento de esta enfermedad busca mejorar los síntomas y puede incluir radioterapia, analgésicos no esteroides que inhiben la formación de calcificaciones y cirugías. Es importante aclarar que, al llegar a indicar una cirugía, es necesario sumar las tres estrategias mencionadas.

Radioterapia: Este tratamiento es fundamental para controlar e incluso disminuir las masas relacionadas con la miositis osificante. Se utiliza tanto en la prevención en cirugías que potencialmente puedan generar miositis osificante, como en el tratamiento quirúrgico de extracción de masas de miositis osificante para prevenir su recidiva. No hay acuerdo sobre la dosis, pero, en general, depende del tamaño, la localización, si es preventiva o coadyuvante.

Antinflamatorios no esteroides: Son los fármacos que más se administran en la profilaxis de la miositis osificante. La indometacina es el patrón de referencia, se administran $25 \mathrm{mg}, 3$ veces por día, durante 6 semanas.

Nuevos estudios muestran buenos resultados con los inhibidores de COX-2, como el celecoxib, para la profilaxis de la miositis osificante.

La indicación quirúrgica de remover la miositis osificante está directamente relacionada con la sintomatología y como afecta la calidad de vida del paciente.

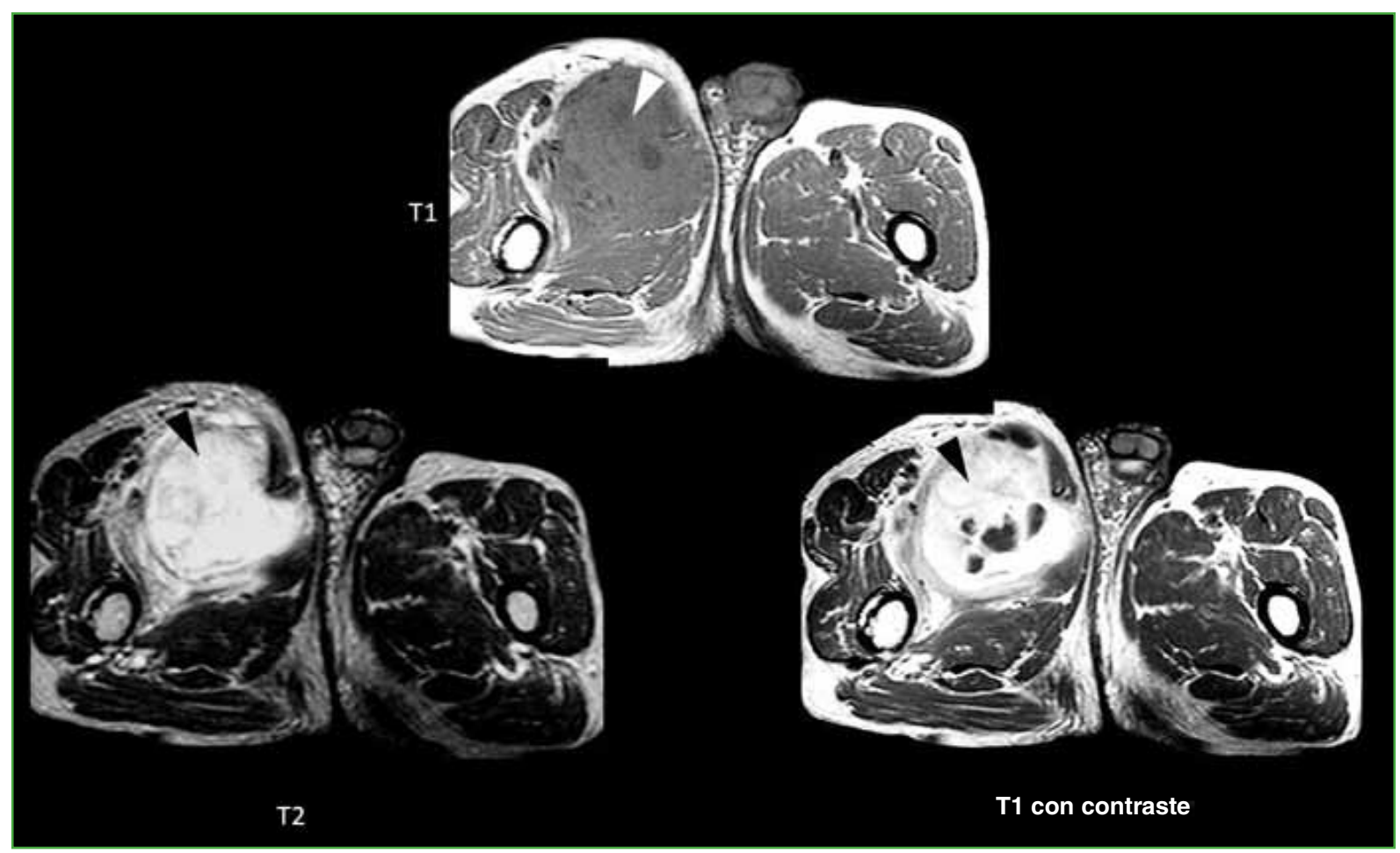

Figura 7. Resonancia magnética de pelvis con medio de contraste. En la secuencia T1, se observa una lesión expansiva con señal intermedia en la región interna del tercio proximal del muslo derecho. En la secuencia T2, la lesión es francamente hiperintensa. Tras la inyección del medio de contraste, se reconoce un marcado refuerzo con áreas centrales de baja señal que no toman el medio de contraste. 


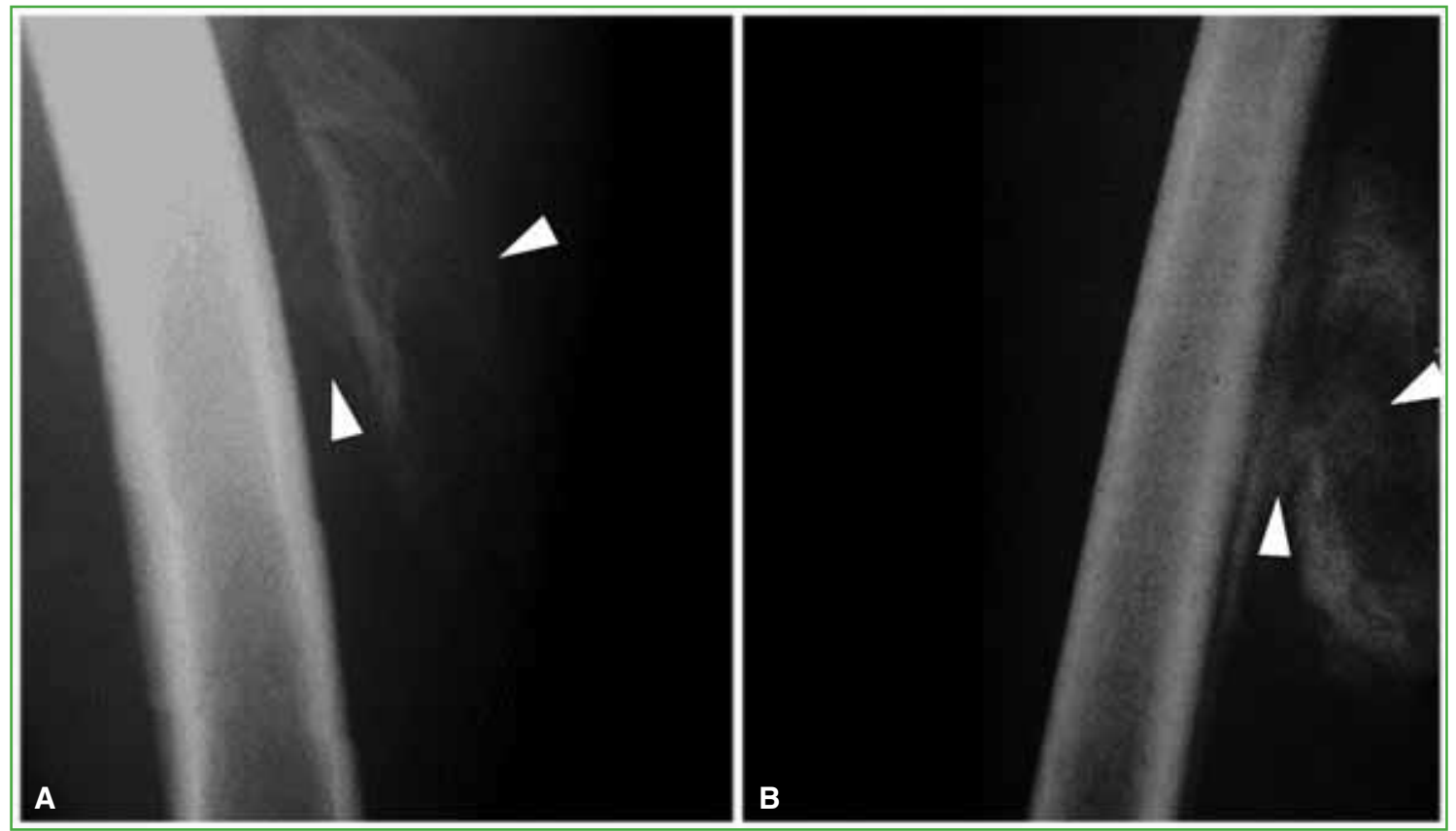

Figura 8. Radiografías de fémur en distintos pacientes que muestran la diferencia entre miositis osificante (A) y osteosarcoma paraostal (B). En la miositis, la calcificación es periférica y se reconoce radiolucidez (hendidura) con el hueso adyacente. En el sarcoma, la calcificación es central y hay continuidad con la estructura ósea vecina.

Un punto importante por aclarar es que la cirugía se debe realizar luego de los 6 meses de la aparición de la miositis osificante, es decir, se debe esperar su "maduración". El porcentaje de recidiva es alto cuando la cirugía se lleva a cabo antes. Es importante recordar que el procedimiento quirúrgico debe ir acompañado de radioterapia profiláctica y antinflamatorios no esteroides.

La paciente presentada fue tratada con una única dosis de radioterapia, fisiokinesioterapia e indometacina $25 \mathrm{mg}$, 3 veces por día, durante 6 semanas, con un buena restitución de la calidad de vida, pero el volumen de la miositis osificante no se redujo significativamente. 